\title{
Brief communication: Using averaged soil moisture estimates to improve the performances of a regional-scale landslide early warning system
}

\author{
Samuele Segoni ${ }^{1}$, Ascanio Rosi ${ }^{1}$, Daniela Lagomarsino ${ }^{1, \text { a }}$, Riccardo Fanti ${ }^{1}$, and Nicola Casagli ${ }^{1}$ \\ ${ }^{1}$ Department of Earth Sciences, University of Florence, Firenze, 50121, Italy \\ ${ }^{a}$ now at: Eni S.p.A, S. Donato Milanese, Milano, Italy
}

Correspondence: Samuele Segoni (samuele.segoni@unifi.it)

Received: 11 October 2017 - Discussion started: 23 October 2017

Revised: 23 January 2018 - Accepted: 18 February 2018 - Published: 13 March 2018

\begin{abstract}
We communicate the results of a preliminary investigation aimed at improving a state-of-the-art RSLEWS (regional-scale landslide early warning system) based on rainfall thresholds by integrating mean soil moisture values averaged over the territorial units of the system. We tested two approaches. The simplest can be easily applied to improve other RSLEWS: it is based on a soil moisture threshold value under which rainfall thresholds are not used because landslides are not expected to occur. Another approach deeply modifies the original RSLEWS: thresholds based on antecedent rainfall accumulated over long periods are substituted with soil moisture thresholds. A back analysis demonstrated that both approaches consistently reduced false alarms, while the second approach reduced missed alarms as well.
\end{abstract}

\section{Introduction}

Regional-scale landslide early warning systems (RSLEWS henceforth) are usually based on empirical rainfall thresholds, which in turn are based on rainfall parameters that can be easily measured and monitored by rain gauges (Aleotti, 2004; Baum et al., 2010; Cannon et al., 2011; Segoni et al., 2015a; Leonarduzzi et al., 2017; Piciullo et al., 2017).

However, it is widely recognized that soil moisture conditions before the triggering rainfall event can play a crucial role in the initiation of landslides, especially when deepseated landslides and terrains with complex hydrological settings are involved (Wieczorek, 1996; Zezere et al., 2005; Je- mec and Komac, 2013; Peres and Cancelliere, 2016; Bogaard and Greco, 2018).

Unfortunately, the influence of soil moisture conditions is difficult to encompass in RSLEWS. One of the most widespread approaches is establishing rainfall thresholds based on the rainfall amount accumulated during a given period before landslide occurrence or before the triggering rainfall event (Kim et al., 1991; Chleborad, 2003). The length of these time spans varies widely in the international literature, e.g., from a few days (Kim et al., 1991; Calvello et al., 2015) to a few months (Zezere et al., 2005). More advanced models combine daily rainfall data to compute antecedent rainfall indexes that can be used to forecast landslide occurrence (Crozier, 1999; Glade et al., 2000). All these methodologies share the approach of considering antecedent rainfall as a proxy for soil moisture. A smaller series of studies takes advantage of remotely sensed soil moisture data (Brocca et al., 2016; Laiolo et al., 2015) but their integration in RSLEWS is not straightforward and it is limited to few case studies (Ponziani et al., 2012).

This work explores the possibility to exploit the estimated mean soil moisture (MSM) value averaged over large (thousands of squared kilometers) territorial units (TUs) to find an empirical correlation with the triggering of landslides.

We tested this hypothesis in the regional warning system of the Emilia Romagna Region (Italy), which is based on the combination of short-term and long-term rainfall measurements to forecast the occurrence of landslides, as described in detail in Martelloni et al. (2012) and Lagomarsino et al. (2013). We developed an alternate version of the RSLEWS, substituting long-term measurements with 
soil moisture estimates obtained by TOPKAPI (TOPographic Kinematic APproximation and Integration), a physically based model (Ciarapica and Todini, 2002). The different versions of the RSLEWS were compared and, given the satisfactory outcomes of the results, we discuss a possible application of the proposed methodology to the regional warning system.

\section{Materials and method}

The test site is the Emilia Romagna Region (Northern Italy). This region is characterized by a morphology ranging from high mountains in the S-SW to wide plains towards NE. The mountain chain of the region belongs to the northern Apennines, which is a complex fold-and-thrust arcuate orogenic belt that originated in response to the closure of the Ligurian Ocean and the subsequent collision of the European and continental margins which started in the Oligocene (Agostini et al., 2013). The mountainous part of the region is affected by surficial and deep-seated landslides, which can be triggered by short and intense rainfalls or by prolonged rainy periods, respectively (Martelloni et al., 2012).

One of the instruments used to manage landslide hazard is a RSLEWS called SIGMA, which is based on a complex decisional algorithm that considers whether the statistical rainfall thresholds are overcome (Martelloni et al., 2012). The thresholds are defined in terms of standard deviation (SD; $\sigma$ ) from the mean rainfall amount accumulated during progressively increasing time steps.

The methodology to develop a sigma model (fully described in Martelloni et al., 2012) is based on the hypothesis that anomalous or extreme values of rainfall are responsible for landslide triggering and multiples of the SD are used as thresholds to discriminate between ordinary and extraordinary rainfall events. To obtain probability values of not exceeding a given rainfall threshold, rainfall time series longer than 50 years are taken into account for each rain gauge. Data of the original rainfall distributions are adapted to a target function chosen as a model (standard Gaussian distribution in this case). After this conversion, it is possible to define any probability of not overcoming by using SD values, which in turn can be related to the corresponding rainfall value of the original data series.

SIGMA algorithm considers two different periods of cumulative rainfall. Daily checks of 1-, 2- and 3-day cumulative rainfall (short period) are used to forecast shallow landslides. A series of daily checks over a longer and variable time window (ranging from 4 to 243 days, depending on the seasonality) is used to forecast deep-seated landslides in lowpermeability terrains (Lagomarsino et al., 2013). To increase the effectiveness of the model, the mountainous part of the region is divided into 25 homogeneous TUs, each monitored by a reference rain gauge, as fully described in Lagomarsino et al. (2013) and depicted in Fig. 1.
For some of the hydrographic basins of the region, ARPAE-ER (Regional Agency for Prevention, Environment, and Energy of Emilia Romagna) provides the MSM value at hourly time step. These values are estimated by TOPKAPI (Ciarapica and Todini, 2002), which is a rainfallrunoff model providing high-resolution hydrological information.

We used these data to estimate the daily MSM value for each TU. We used daily aggregation because SIGMA is normally run daily, and it uses daily aggregations of hourly rainfall measurements; therefore, a higher temporal resolution would be unnecessary. In case the territory of some TUs is occupied by more than one basin, a weighted mean was used to obtain an averaged value.

Similarly, since the final objective of this work is to couple soil moisture data with rainfall data measured over discrete points (a network of rain gauges, one for each TU), we are not interested into distributed modeling of soil moisture, but a single soil moisture value is needed for each TU. This approach is not completely new, as in the same test site Martelloni et al. (2013) used punctual measurements of temperature to incorporate in SIGMA a module accounting for snow accumulation-depletion processes.

\section{Alternate approaches}

\subsection{A preliminary test: the MSM threshold}

We compared all landslide occurrences in the years 20092014 and MSM at each TU. We verified that for each TU a threshold MSM value can be identified under which landslides have never been reported, independently of the rainfall amount. In addition, we verified that in general TUs had similar threshold MSM, with a few exceptions. Threshold MSM is $75 \%$ in TU23 and TU22, $76 \%$ in TU18, $78 \%$ in TU17, and $79 \%$ in TU19. In TU21, the threshold MSM is $88 \%$. This value is higher than all other TUs and it can be partially explained with the scarcity of data: only four landslide events are included in the testing data set of TU21. TU20 presents a landslide event with 54\% MSM. If we consider this event as an outlier and we exclude it from the analysis, the value is also $75 \%$ for TU20.

Consequently, taking a MSM threshold into account could prevent SIGMA from committing false alarms in case of abundant rainfalls outside the rainy season, when the soil is dry. Therefore, we modified SIGMA algorithm by adding a cutoff threshold defined as MSM $=75 \%$, which is the arithmetic mean of the values of each TU. Basically, the modified version of the algorithm checks the daily MSM value reported for a given TU and compares it with the $\mathrm{MSM}=75 \%$ threshold. Under this value, no landslide is expected and the SIGMA algorithm is not launched. When daily MSM is higher than $75 \%$, landslides can be expected when particular rainfall conditions are verified - therefore 


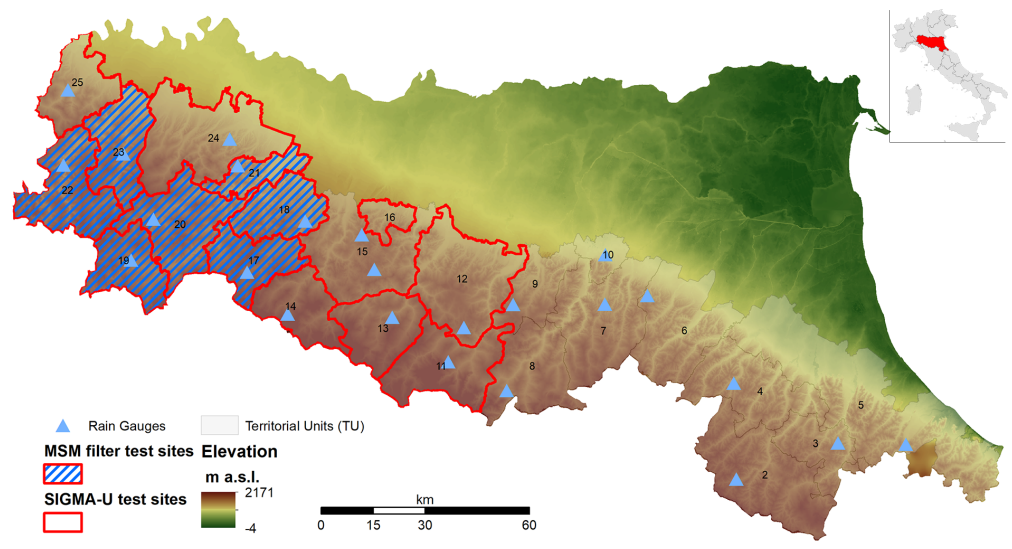

Figure 1. Test site showing the partition in territorial units (TUs) and highlighting the TUs used as test sites.

SIGMA algorithm is launched. We set a MSM threshold equal for all TUs because in some TUs the landslide data set contains only a few events (e.g., only four landslide events in TU21) and a dedicated MSM threshold value would be characterized by a very weak empirical correlation that would prevent a safe use in the RSLEWS. In addition, if we exclude the outliers, all TUs are characterized by small variations in MSM threshold values (from 75 to $79 \%$ ). We therefore decided to renounce the "detail" of the personalized threshold in favor of a more robust MSM threshold generalized for the whole test area.

A back analysis performed for the years 2009-2014 over the seven test TUs shows a marked reduction of false alarms (days in which the rainfall thresholds are exceeded but no landslides are reported). More in detail: false alarms in the first warning level decreased from 320 to $231(-28 \%)$, false alarms in the second warning level decreased from 169 to 141 $(-17 \%)$ and false alarms in the third warning level decreased from 13 to $5(-62 \%)$. To correctly evaluate the effectiveness of a EWS, the improvement concerning false alarms should be weighed against the behavior concerning missed alarms (days in which the rainfall thresholds are not exceeded but landslides are reported). We verified that the introduction of the MSM threshold caused the increase of missed alarm counts only by one: the already mentioned event occurred in 1 June 2013, consisting in three landslides (lowest alarm level according to Lagomarsino et al., 2013). Since this was a minor event and since lowering the MSM threshold to $54 \%$ would result in an almost total loss of the benefits in terms of false alarm reduction, the $75 \%$ threshold was considered successfully tested and the 1 June 2013 event was considered an acceptable trade-off for a general improvement of the warning system.

It should be noted that the described use of the MSM threshold is not capable of reducing the missed alarms committed by SIGMA, as it acts like a cutoff filter. To obtain a reduction of both missed and false alarms, a more radical modification of SIGMA is depicted in the next section.

\subsection{SIGMA-U}

After the preliminary but encouraging results described in the previous section, we decided to integrate soil moisture thresholds more deeply into the original SIGMA algorithm, and we substituted rainfall thresholds based on long accumulation periods with statistical soil moisture thresholds. Following the same procedure used in Martelloni et al. (2012) for rainfall data to build $\sigma$ curves, we calculated for every TU the time series of soil moisture $(u)$, assessing the mean values and the SDs. After this procedure, for each TU every soil moisture value $(U)$ could be expressed in terms of multiples of SD from $u$.

After that, we deeply modified the original decisional algorithm of SIGMA, discarding all the long-period rainfall $\sigma$ curves in favor of soil moisture $\sigma$ curves. While the former rainfall $\sigma$ curves were checked for long periods up to 243 days, the new soil moisture $\sigma$ curves are checked for cumulative periods ranging from 1 to 15 days, at 1-day increasing time steps. Rainfall thresholds based on rainfall sigma curves are still present in the new version of the algorithm, but are used only for short periods (1-, 2- and 3-day antecedent rainfall). The new version of the algorithm, which was called SIGMA-U, is shown in Fig. 2.

A back analysis was performed using landslide, soil moisture and rainfall data from the period 2011-2014 to compare the performances of SIGMA and SIGMA-U. The test was performed in all TUs where soil moisture values were available (14 out of 25, as shown in Fig. 1) and the results are summarized in Table 1.

The results of the back analysis are encouraging, as the count of both false alarms and missed alarms is lower in SIGMA-U than in SIGMA. Concerning false alarms, the more dangerous the alarm level is, the higher the reduction: false alarms corresponding to the first warning level, which are negligible, decreased by $8 \%$, while the very important warning level 3 was erroneously issued 11 times instead of $21(-48 \%)$. False alarms at the intermediate warning level 2 


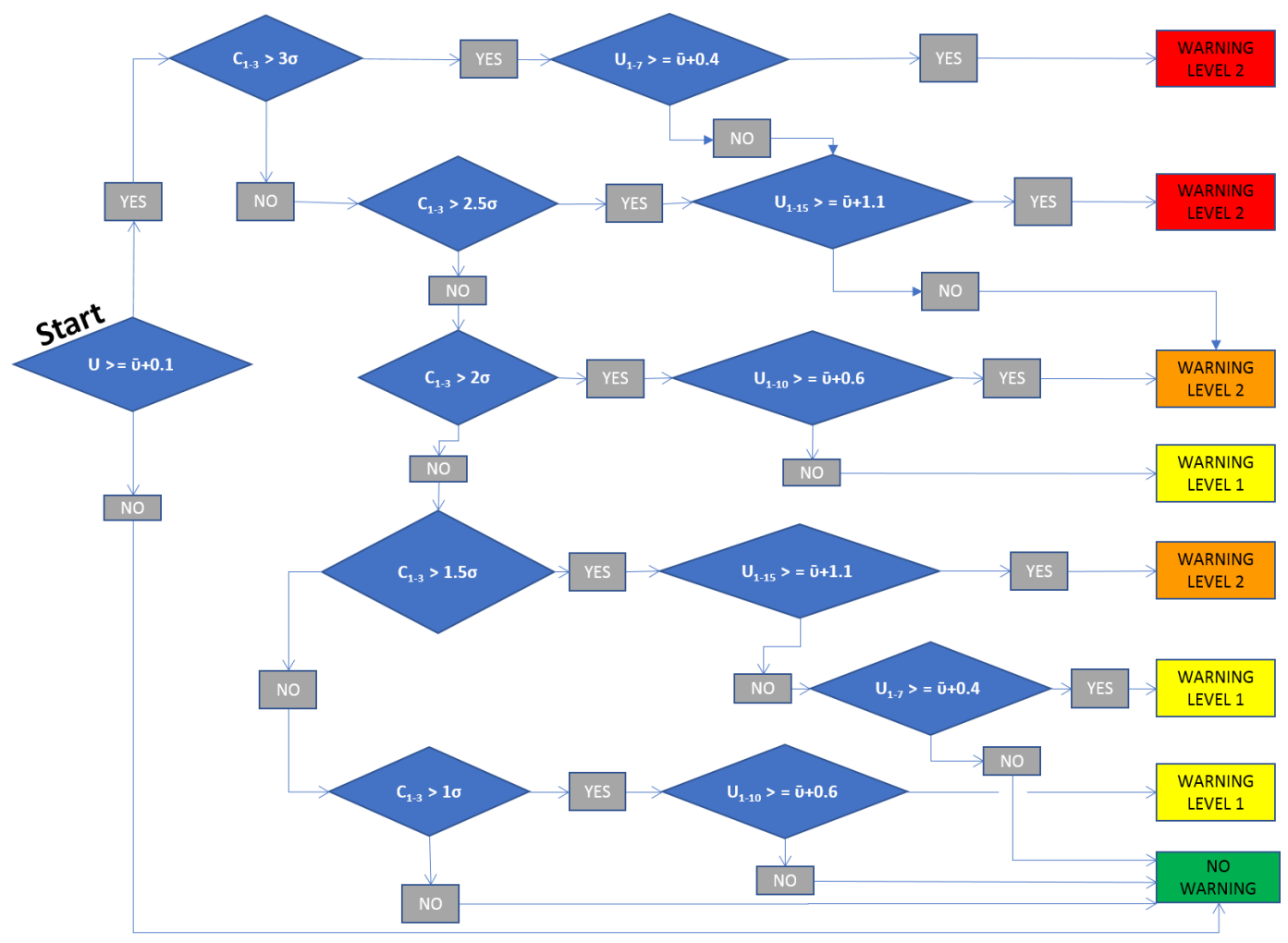

Figure 2. Scheme of the SIGMA-U algorithm. $\mathrm{C}$ is cumulative rainfall, $\mathrm{U}$ is soil moisture, and $\bar{v}$ is average soil moisture.

Table 1. Quantitative evaluation of the performances of the models SIGMA (Lagomarsino et al., 2013) and SIGMA-U (this paper).

\begin{tabular}{llrrrr}
\hline & & SIGMA & SIGMA-U & Variation & Variation (\%) \\
\hline \multirow{2}{*}{ False alarms } & Warning level 1 & 780 & 721 & -59 & $-8 \%$ \\
& Warning level 2 & 287 & 197 & -90 & $-31 \%$ \\
& Warning level 3 & 21 & 11 & -10 & $-48 \%$ \\
\hline \multirow{2}{*}{ Missed alarms } & Number of alarms & 88 & 69 & -19 & $-22 \%$ \\
& Number of missed landslides & 214 & 134 & -80 & $-37 \%$ \\
\hline \multirow{2}{*}{ Hits } & Number of landslides & 709 & 789 & +80 & $+11 \%$ \\
& $\%$ of total landslides & 76.8 & 85.5 & +8.7 & $+11 \%$ \\
\hline
\end{tabular}

were reduced from 287 to 197 ( $-31 \%)$. Missed alarms were reduced as well: while SIGMA missed 88 alarms, SIGMA$\mathrm{U}$ missed 69 alarms $(-22 \%)$. This corresponds to a total of 134 missed landslides instead of $214(-37 \%)$. Overall, SIGMA-U hits 789 landslides out of 923 (85.5\%), outperforming SIGMA, which hits 709 landslides (76.8\%).

\section{Conclusions}

We communicate the results of a preliminary investigation aimed at improving a state-of-the-art RSLEWS based on rainfall thresholds (SIGMA; Martelloni et al., 2012; Lagomarsino et al., 2013) by integrating mean soil moisture values averaged over the territorial units of the system. We tested two different approaches. The first approach is the simplest: it is based on a soil moisture threshold value $(75 \%$ in this study) under which rainfall thresholds are not used because landslides are not expected to occur. When tested with a back analysis, this approach reduced consistently false alarms but produced an additional missed alarm. This approach is very simple and can be easily replicated in other cases of study after a straightforward calibration against the local soil moisture and landslide data sets.

The second approach is more complex and relies on the idea that rainfall thresholds based on antecedent rainfall accumulated over very long periods can be substituted with 
soil moisture thresholds. A back analysis demonstrated that a new version of the model based on soil moisture and shortterm rainfall could be more effective than the original version based on short-term rainfall and long-term rainfall, as both false alarms and missed alarms were consistently reduced.

Some recent studies criticized the traditional rainfall threshold approach based only on rainfall variables and stressed the importance of considering additional factors such as soil moisture to better encompass the hydrologic conditions of landsliding slopes (Bogaard and Greco, 2018; Canli et al., 2017). The present work follows the direction expressed by the aforementioned series of works and presents a small advance towards a sounder (and more effective) hydrologic approach to identify rainfall thresholds for landslide occurrence.

The research is still ongoing and further tests are needed before arriving to a full integration with the regional landslide warning system of Emilia Romagna. These tests include (i) the use of soil moisture measurements coming from other sources (e.g., remotely sensed data or direct measurements at selected test sites); (ii) the refinement of the spatial resolution of the alerts by integrating soil moisture measurements, rainfall thresholds and susceptibility maps (Segoni et al., 2015b); (iii) the improvement of the model taking into account different threshold values of sigma for each TU, after a thorough site-specific calibration; and (iv) a thorough validation of the model.

Data availability. Rainfall and soil moisture data are publicly available and are organized in DEXT3R, a public repository managed by ARPAE-Emilia Romagna. DEXT3R can be accessed upon registration at the URL http://www.smr.arpa.emr.it/dext3r/.

Special issue statement. This article is part of the special issue "Landslide early warning systems: monitoring systems, rainfall thresholds, warning models, performance evaluation and risk perception". It is not associated with a conference.

Edited by: Thomas Glade

Reviewed by: two anonymous referees

\section{References}

Agostini, A., Tofani, V., Nolesini, T., Gigli, G., Tanteri, L., Rosi, A., Cardellini, S., and Casagli, N.: A new appraisal of the Ancona landslide based on geotechnical investigations and stability modelling, Q. J. Eng. Geol. Hydroge., 47, 29-43, https://doi.org/10.1144/qjegh2013-028, 2013.

Aleotti, P.: A warning system for rainfall-induced shallow failures, Eng. Geol., 73, 247-265, 2004.

Baum, R. L. and Godt, J. W.: Early warning of rainfall-induced shallow landslides and debris flows in the USA, Landslides, 7, 259272,2010
Bogaard, T. and Greco, R.: Invited perspectives: Hydrological perspectives on precipitation intensity-duration thresholds for landslide initiation: proposing hydro-meteorological thresholds, Nat. Hazards Earth Syst. Sci., 18, 31-39, https://doi.org/10.5194/nhess-18-31-2018, 2018.

Brocca, L., Ciabatta, L., Moramarco, T., Ponziani, F., Berni, N., Wagner, W., Petropoulos, G. P., Srivastava, P., and Kerr, Y.: Use of satellite soil moisture products for the operational mitigation of landslides risk in central Italy, in: Satellite Soil Moisture Retrievals: Techniques \& Applications, Elsevier, Amsterdam, the Netherlands, 231-247, 2016.

Calvello, M., d'Orsi, R. N., Piciullo, L., Paes, N., Magalhaes, M. A., and Lacerda, W. A.: The Rio de Janeiro early warning system for rainfall-induced landslides: analysis of performance for the years 2010-2013, Int. J. Disast. Risk Re., 12, 3-15, https://doi.org/10.1016/j.ijdrr.2014.10.005, 2015.

Canli, E., Mergili, M., and Glade, T.: Probabilistic landslide ensemble prediction systems: Lessons to be learned from hydrology, Nat. Hazards Earth Syst. Sci. Discuss., https://doi.org/10.5194/nhess-2017-427, in review, 2017.

Cannon, S., Boldt, E., Laber, J., Kean, J., and Staley, D: Rainfall intensity duration thresholds for postfire debris-flow emergency response planning, Nat. Hazards, 59, 209-236, 2011.

Chleborad, A. F.: Preliminary evaluation of a precipitation threshold for anticipating the occurrence of landslides in the Seattle, Washington, Area, US Geological Survey Open-File Report 03, 463 pp., 2003.

Ciarapica, L. and Todini, E.: TOPKAPI: A model for the representation of the rainfall-runoff process at different scales, Hydrol Process., 16, 207-229, 2002.

Crozier, M. J.: Prediction of rainfall-triggered landslides: a test of the Antecedent Water Status Model, Earth Surf. Proc. Land., 24, 825-833, 1999.

Glade, T., Crozier, M., and Smith, P.: Applying probability determination to refine landslide-triggering rainfall thresholds using an empirical “Antecedent Daily Rainfall Model”, Pure Appl. Geophys., 157, 1059-1079, 2000.

Jemec, M. and Komac, M.: Rainfall patterns for shallow landsliding in perialpine Slovenia, Nat. Hazards, 67, 1011-1023, 2013.

Kim, S. K., Hong, W. P., and Kim, Y. M.: Prediction of rainfall triggered landslides in Korea, in: Landslides, vol. 2, edited by: Bell, D. H., A. A. Balkema, Rotterdam, 989-994, 1991.

Lagomarsino, D., Segoni, S., Fanti, R., and Catani, F.: Updating and tuning a regional-scale landslide early warning system, Landslides, 10, 91-97, 2013.

Laiolo, P., Gabellani, S., Campo, L., Silvestro, F., Delogu, F., Rudari, R., and Crapolicchio, R.: Impact of different satellite soil moisture products on the predictions of a continuous distributed hydrological model, Int. J. Appl. Earth Obs., 48, 131145, https://doi.org/10.1016/j.jag.2015.06.002, 2015.

Leonarduzzi, E., Molnar, P., and McArdell, B. W.: Predictive performance of rainfall thresholds for shallow landslides in Switzerland from gridded daily data, Water Resour. Res., 53, 6612-6625, 2017.

Martelloni, G., Segoni, S., Fanti, R., and Catani, F.: Rainfall thresholds for the forecasting of landslide occurrence at regional scale, Landslides, 9, 485-495, 2012.

Martelloni, G., Segoni, S., Lagomarsino, D., Fanti, R., and Catani, F.: Snow accumulation/melting model (SAMM) for integrated 
use in regional scale landslide early warning systems, Hydrol. Earth Syst. Sci., 17, 1229-1240, https://doi.org/10.5194/hess-171229-2013, 2013.

Peres, D. J. and Cancelliere, A.: Estimating return period of landslide triggering by Monte Carlo simulation, J. Hydrol., 541, 256271, 2016.

Piciullo, L., Gariano, S. L., Melillo, M., Brunetti, M. T., Peruccacci, S., Guzzetti, F., and Calvello, M.: Definition and performance of a threshold-based regional early warning model for rainfall-induced landslides, Landslides, 14, 995-1008, https://doi.org/10.1007/s10346-016-0750-2, 2017.

Ponziani, F., Pandolfo, C., Stelluti, M., Berni, N., Brocca, L., and Moramarco, T.: Assessment of rainfall thresholds and soil moisture modeling for operational hydrogeological risk prevention in the Umbria region (central Italy), Landslides, 9, 229-237, 2012.

Segoni, S., Battistini, A., Rossi, G., Rosi, A., Lagomarsino, D., Catani, F., Moretti, S., and Casagli, N.: Technical Note: An operational landslide early warning system at regional scale based on space-time-variable rainfall thresholds, Nat. Hazards Earth Syst. Sci., 15, 853-861, https://doi.org/10.5194/nhess-15-8532015, 2015a.
Segoni, S., Lagomarsino, D., Fanti, R., Moretti, S., and Casagli, N.: Integration of rainfall thresholds and susceptibility maps in the Emilia Romagna (Italy) regional-scale landslide warning system, Landslides, 12, 773-785, 2015b.

Wieczorek, G. F.: Landslide triggering mechanism, in: Landslides investigation and mitigation, special report. Transportation Research Board, 247, edited by: Turner, A. K. and Schuster, R. L., National Academy Press, Washington, 76-89, 1996.

Zêzere, J. L., Trigo, R. M., and Trigo, I. F.: Shallow and deep landslides induced by rainfall in the Lisbon region (Portugal): assessment of relationships with the North Atlantic Oscillation, Nat. Hazards Earth Syst. Sci., 5, 331-344, https://doi.org/10.5194/nhess-5-331-2005, 2005. 